\title{
Marcos conceituais do atendimento integral ao idoso*
}

\author{
Antonio Augusto F. Quadra** \\ Luiz Carlos Araújo*** \\ Dimário Pereira da Costa****
}

\begin{abstract}
"Inclusive porque esses velhos, em prazo mais curto do que imaginamos ou desejamos, seremos nós mesmos". (Aloysio Amancio e P.C.U. Cavalcanti)
\end{abstract}

Segundo estimativas grosseiras, o homem está na face da Terra há uns 600 mil anos e a História, reconhecida como sua capacidade de transformar a natureza estaria sendo exercida há perto de pouco mais de 6 mil anos. Em todo esse período de tempo, absolutamente inalcançável pelo raciocínio lógico, o fenômeno velhice é algo paradoxal mente novo.

Apenas muito recentemente com a introdução de técnicas do que, a princípio, se chamou de "aritmética política" e, mais tarde, "demografia", levantamentos sistemáticos periódicos passaram a reconhecer a velhice como uma categoria biológica e, a seguir, social ${ }^{(1)}$.

$\mathrm{Na}$ primeira metade deste século, a "reposição" da população humana duplicou (taxa de natalidade), ao passo que a população maior do que 60 anos quadriplicou ${ }^{(2)}$.

Conforme dados e projeções da Organização Mundial da Saúde, a população com mais de 65

*Trabalho realizado no Instituto Municipal de Geriatria e Gerontologia Miguel Pedro.

**Faculdade de Ciências Médicas da UERJ.

***Faculdade de Ciências Médicas da UERJ. Presidente do Centro de Estudos do Instituto Municipal de Geriatria e Gerontologia Miguel Pedro.

****Diretor do Instituto Municipal de Geriatria e Gerontologia Miguel Pedro. anos de idade que, no início desta década, era de 291 milhões de pessoas, no ano 2000 - portanto, daqui a 20 anos - será de 585 milhões ${ }^{(3)}$.

Apesar, portanto, de sua modernidade, a velhice não deixou de ser incluída por OZBEKHAN ${ }^{(4)}$ entre os problemas que denominou de "críticos contínuos": universais, inquestionáveis, carentes de estudos multidisciplinares e de ações basicamente governamentais e multissetoriais. Assim, se especificamente a "discriminação para com as pessoas de idade avançada" é em si um problema crítico contínuo conspícuo, concorrem para o agravamento dele outros tantos agregados, tais como: "pobreza generalizada", "discriminação contra minorias", "programas de bem estar social obsoletos", "assistência médica insuficiente". Em cada uma dessas categorias, o idoso comparece como vítima de uma ordem social injusta.

\section{Limite e Expectativa da Vida: Algumas Tendên- cias Propícias à Longevidade}

O tempo de duração de uma vida humana média na Roma Antiga era de 23 anos e, apesar das talvez fantásticas figuras de personagens sábios e idosos que povoam o Velho Testamento, são as atuações de jovens como Alexandre, César ou 
Cristo que vão marcar toda uma época ${ }^{(1),(5)}$. Hoje, toma-se até vulgar intuir que as condições sanitárias absolutamente precárias, as epidemias de diversas formas de veiculação, os acidentes, as guerras e conquistas se transformaram durante séculos em poderosos consumidores de vidas e não era absurdo que caso alguém atingisse 50 ou 60 anos de idade se transfigurasse em alguma espécie de semidivindade.

Há uns 4 milhões de anos, o Australopitecus africanus parecia ter uma expectativa máxima de vida de uns 50 anos, similar ao orangotango atual ${ }^{(1)}$; estima-se, por igual, que desde o surgimento da espécie Homo, o seu potencial biológico não se tenha alterado $^{(1)}$, ou seja, o programa da vida inserido nos genes persiste imutável.

O fenômeno singular que nos deterá mais a seguir é: o limite proposto à vida não se modificou, mas a expectativa de vida sim. Isto é, o potencial genético próprio de que a espécie humana desfruta, pode levá-la, ao máximo, a uma centena de anos, o que é seguramente uma utopia para quase todas as populações. Isto evidentemente não denuncia uma limitação biológica de se atingir uma meta, mas tão somente revela intransponíveis obstáculos sociais, os já mencionados "problemas críticos contínuos"(4).

"Segundo um estudo das Nações Unidas, a esperança de vida passou de 64,6 anos para 70,4 anos nos países desenvolvidos, entre 1950 e 1970. Nos países em vias de desenvolvimento, ela aumentou quase 8 anos, de 41,7 para 49,6 . Na África Ocidental, é que a esperança de vida é mais curta; de 32,5 em 1950, atingiu 39,2 em 1970"(6). Obviamente, não se trata de qualquer problema biológico.

Nos últimos anos da década de ' 60 , as mulheres da Áustria, Bélgica, Canadá, França, Espanha, Itália, Países Baixos, República Federal da Alemanha e Suíça já exibiam uma esperança de vida ao nascer maior do que 70 anos, oscilando entre 71,9 e 76,4 $\operatorname{anos}^{(7)}$. Mesmo os homens dos Países Baixos já apresentavam uma esperança de $71 \operatorname{anos}^{(7)}$.
REVISTA BRASILEIRA DE EDUCAÇÃO MÉDICA

No final da década de ' 60 , a Áustria, Bélgica, França, Itália, Países Baixos, República Federal da Alemanha e Suíça contavam com uma participação percentual da população de 65 anos e mais, superior a $10 \%$, alcançando no primeiro desses países cifras de $14 \%{ }^{(7)}$.

No Brasil, exceto segundo os Dados Censitários de 1872, que talvez imprecisa mente, diziam existir $7,6 \%$ de pessoas com 60 anos e mais, os últimos levantamentos decenais oficiais situam a participação percentual entre os 4 e $5 \%$, ao correr do século, mesmo nas áreas mais desenvolvidas ${ }^{(8)}$. As extrapolações para o ano 2000 , situam a população maior de 60 anos participando com um contingente que varia entre 6,22 e $6,87 \%$ dos residentes ${ }^{(8)}$. Para o ano de 1976, as estimativas eram de que tal grupo concorria com 5,9\% do total, sendo na área urbana representativa de $6,14 \%{ }^{(8)}$. O Estado do Rio de Janeiro apresentava um índice superior ao nacional, tendo, acima de 60 anos de idade, cerca de $6,71 \%$ de seus habitantes ${ }^{(8)}$.

É evidente que, em última análise, a questão do envelhecimento das populações vai depender da ponderação entre nascimentos e óbitos, mas o que persiste relevante é a época do óbito. Embora existam aqueles que acreditam ter sido a diminuição da mortalidade infantil uma das causas preponderantes para o aumento do número de velhos $^{(9)}$, outros pesquisadores admitem que em países como o Brasil, as taxas de mortalidade infantil não experimentaram, neste século, queda suficientemente significativa e constante a ponto de alterar substancialmente por si a média de vida do conjunto da população ${ }^{(10)}$. Na verdade, alterações atribuíveis a tal fator podem ter seus efeitos medidos apenas a prazo mais longo; assim, é provável que naqueles países que já há muitas décadas, por seu desenvolvimento econômico, conseguiram decrescer seus níveis de mortalidade infantil às proximidades do chamado "resíduo irredutível", tal elemento seja ponderável na explicação da longevidade alcançada. 
Paradoxalmente, alguns países têm experimentado quedas na longevidade às custas do aumento dos índices de mortes por acidentes e violências. Nos Estados Unidos, entre 1960 e 1974, tal taxa cresceu em mais de $100 \%$; nos anos recentes, o risco de um recém-nascido norte-americano vir a morrer por assassinato oscila entre 2 e $5 \%$, sendo que breve em cada 12 óbitos, 1 será por violência. Isto parece ter reduzido a esperança de vida nos Estados Unidos em 3 anos ${ }^{(11)}$.

Apesar de alguns estudos temerem um envelhecimento progressivo das populações às custas da adoção de políticas anti-natalistas ${ }^{(9)}$, o que se observa é que a despeito de alguns descomunais esforços no sentido da redução drástica das taxas de natalidade, é quase um truismo dizer-se que a estabilização de nascimentos e a conseqüente redução da fertilidade decorre do desenvolvimento econômico e de uma efetiva motivação social e familiar; jamais de programas ostensivos ou velados de controle populacional, como o clássico exemplo da Índia. Assim, antes dos horrores "malthusianos", o que tende a ser observado é um "saldo" entre nascer e morrer, proposto a partir de uma equânime distribuição da riqueza entre todos os segmentos populacionais.

Parece uma discussão mais fecunda a relativa a mudanças indiscutíveis ocorridas no presente século, mormente: o saneamento básico em seu sentido amplo, a vacinação compulsória, o aumento da escolaridade e a melhoria das condições concretas de exercício do trabalho. Tais medidas, em especial, as duas primeiras, visaram a controlar ou mesmo a erradicar as doenças infecto-contagiosas mais prevalentes e letais. Contudo, mais relevante do que tudo, temos a melhoria do nível sócio-econômico das populações com a incessante luta por relações de produção mais justas.

O mais evidente indicador das alterações experimentadas pela longevidade pode ser extraído das modificações do perfil de causas de morte. Assim, como exemplo, nos Estados Unidos, em 1900, as três primeiras causas eram, respectivamente: tuberculose, pneumonia e gastrenterite; em 1950, já eram as cardiopatias, neoplasias malignas e as lesões vasculares do sistema nervoso central ${ }^{(2)}$.

"Em numerosos países, as doenças cardiovasculares foram responsáveis por mais de 40\% dos óbitos. Assim concorreu, em 1969, na Austrália com 55\%, na Hungria com 54,3\%, nos Estados Unidos com 53,9\%, na Suécia com 52,4\%, na Irlanda com 51,3\%, na Nova Zelândia com $51,2 \%$, na Noruega com $50 \% \ldots{ }^{. .}{ }^{(6)}$.

Se, por um lado, o nosso país ainda se caracteriza por uma população preponderan temente jovem, por um nível de natalidade relativamente alto e ainda por um padrão de mortalidade onde avultam as doenças redutíveis por saneamento e imunização, há bolsões cuja composição semelhante a dos países ricos propiciam o aparecimento do fenômeno velhice como relevante ${ }^{(12)}$.

Nesse contexto, a situação do município do Rio de Janeiro é particularmente interessante e convém transcrever excerto de recente publicação do Sindicato dos Médicos do Rio de Janeiro que, na análise de alguns indicadores de saúde, declara: "Entre 1957 e 1959, as 'gastrites, duodenites, enterites e colites, exceto a diarréia do recém nascido' foram as primeiras causas de morte, com um peso relativo no total de óbitos que oscilou entre $11 \%$ e $10 \%$; no ano de 1960 , ocupa o $3^{\circ}$ lugar ( $9 \%$ dos óbitos) e a partir daí abandona o rol das primeiras 5 causas de morte;... As principais doenças degenerativas, 'tumores malignos, incluindo os neoplasmas do tecido linfático e órgãos hematopoéticos', 'doenças cerebrovasculares' e 'doenças isquêmicas do coração' dobram sua importância como causas de morte no período, passando de pouco mais da quinta parte do total de mortes para aproximadamente $40 \%$ "(13). Assim, atualmente, no Rio de Janeiro, os tumores malignos, as doenças isquêmicas do coração e as doenças cerebrovasculares competem pelas três primeiras causas de morte, 
REVISTA BRASILEIRA DE EDUCAÇÃO MÉDICA

caracterizando um padrão de mortalidade típico de uma sociedade que já suplantou parte de seus problemas sanitários básicos e que conta com uma população cujo envelhecimento acaba por propiciar o aparecimento das chamadas doenças crônico-degenerativas.

Um estudo sobre a mortalidade no então Estado da Guanabara declara: "A idade média de ocorrência de óbito aumentou no sexo masculino de 35,8 anos em 1950 para 40,3 em 1960 e a 47,7 em 1970 e, no sexo feminino, de 38,3 em 1950 para 43,7 em 1960 e 53,6 em 1970"(14). Mais adiante: "A esperança de vida ao nascer no sexo masculino aumentou de 50,14 anos em 1959-61 para 57,62 em 1960-71 e, no sexo feminino, o aumento foi respectivamente de 57,41 para 62,42 e $65,89^{\prime \prime(14) . ~}$

Um outro indicador de saúde valioso para o estudo do significado da população idosa em uma dada região e de execução extremamente simples é a chamada taxa de mortalidade proporcional, qual seja, a ponderação em uma fração entre o total de óbitos de pessoas com 50 anos e mais (numerador) e o total de óbitos (denominador). Ora, em uma situação ideal em que todos os habitantes morressem após o $50 .^{\circ}$ aniversário, a taxa igualaria a unidade. É impressionante a fidedignidade de tal indicador, porque as regiões e países que já atingiram quantitativos importantes de mortes por causas cardiovasculares e neoplásicas apresentam taxas de mortalidade proporcional superiores a 0,8 , ou seja, a $80 \%$. Muitas capitais brasileiras sequer atingiram ainda $20 \%$, isto significando que nem $20 \%$ dos habitantes conseguem completar os 50 anos de vida.

\section{Velhice é Doença}

Uma ruptura indispensável a ser feita é a da superposição, consciente ou não, entre velhice e doença ou, sendo mais específico, entre o envelhecimento fisiológico e doenças na velhice.

"Com efeito, é de uso comum o diagnóstico biológico de velhice na medida em que aparecem os sinais de degeneração celular, em maior ou menor grau. Estes sinais, entretanto, não aparecem aos 65 anos e sim muito tempo antes. Ainda que se tome como denominador comum do padrão de velhice a degeneração vascular, sabe-se que estudos histológicos de artérias de jovens soldados americanos mortos na guerra da Coréia demonstravam claramente evidências de arteriosclerose" ${ }^{\prime(5)}$.

Obviamente, com o passar dos anos, por exemplo, os mecanismos de defesa imunológica podem ter a sua eficácia diminuída; no entanto, uma criança sofre a mesma vulnerabilidade e, nem por isso, dir-se-ia que infância é sinônimo de doença. Também é claro que na medida em que se vai vivendo mais tempo, maior é o risco de morte, já se tendo inclusive estimado que, a partir dos 30 anos de idade, tal probabilidade dobra a cada 7 anos $^{(1)}$. Trata-se, novamente, de um risco securitário estimável, não de uma doença classicamente configurada.

O esforço que sugerimos seja feito é no sentido de compreender a velhice (e suas particularidades) como um estágio do evoluir tão natural quanto o de embrião, feto, recém-nascido, criança, adolescente, adulto jovem, adulto maduro. São instantâneos do que se convencionou chamar vida; da história natural da vida do homem.

\section{O Atendimento Integral Ao Idoso}

Uma proposição recente do Ministério da Previdência e Assistência Social dizia: "Trata-se de colocar à disposição da comunidade recursos institucionais existentes que permitam o atendimento à clientela idosa, abrigada, ou não, resultando na diminuição gradativa da demanda nos ambulatórios e hospitais"(15). Antes de precipitadamente se acreditar que a presente frase vise a restringir o atendimento ambulatorial ao velho, o que ela sugere é que a clientela idosa merece uma atenção comunitária, simplificada e institucional. Repele o 
asilo, a internação hospitalar e o atendimento por especialistas. Haverá situações em que à solução asilar será indispensável; em muitos momentos, o leito hospitalar será ocupado; outras tantas vezes, chamar-se-á o especialista. Porém, jamais como norma, como política.

Um breve diagnóstico dessa questão já foi feito em nosso meio por AMANCIO: "A medicina de velhos, entre nós, particular mente no Rio de Janeiro, ou se restringe ao atendimento clínico de velhos doentes, por médicos particulares ou instituições públicas ou privadas, ou inclui apenas a internação em casas de repouso, asilos ou comunidades religiosas ou raciais, sem nenhuma preocupação na recuperação social do velho ou, muito menos, em programas de educação das gerações mais jovens sobre o processo biológico e social do envelhecimento"(12).

O módulo básico para a implantação de um projeto ambulatorial que servisse ao cuidado integral do idoso, seria constituído de quatro unidades $(*)$ de consulta, a saber:

I - Unidade de Atendimento de Medicina (UAM)

II - Unidade de Atendimento de Enfermagem (UAE)

III - Unidade de Atendimento de Psicologia (UAP)

IV - Unidade de Atendimento de Ser viço Social (UAS)

A Unidade de Atendimento de Medicina (UAM), em uma concepção, se destinaria ao primeiro contato com o idoso, representando, em certo sentido, a porta-de-entrada do sistema. “... existem muitos casos... em que as pessoas idosas apreciam manter um relacionamento permanente com o clínico simplesmente na expectativa de encontrar atenção, carinho e amizade"(16). Não

(*) Adotamos a definição de unidade como "conjunto de elementos funcionalmente agrupados, onde são executados atividades afins, visando ao melhor atendimento ao paciente, dando-lhe conforto, segurança e facilitando o trabalho do pessoal"(17). devemos estar desatentos para o fato de que na maioria dos serviços de saúde, o maior contingente de pessoas pensa carecer de atendimento médico; na verdade, precisam, de fato, bem mais de outras formas de atenção social, proporcionáveis talvez por outras estruturas.

Uma outra razão para se ter a UAM como porta-de-entrada do programa seria de cunho epidemiológico; sendo atendida como população preferentemente de 60 anos e mais, admite-se uma prevalência e um risco maiores de condições físicas que requeiram um primeiro exame clínico acurado, um plano de tratamento e um esquema de seguimento.

Precipuamente, a UAM deve ter um quadro de médicos gerais, com formação em Medicina Integral, porém poderá comportar diversas subunidades. Por exemplo: um setor especializado em medidas de prevenção terciária, especificamente voltado à recuperação de pacientes com sequelas e agravos ortopédicos e neurológicos, tais como fraturas, acidentes vasculares encefálicos etc. Uma outra subunidade poderia ter fulcro na assistência e na pesquisa a nível da Nutrição e Dietética.

Diferentemente dos pacientes jovens para os quais a boa técnica do diagnóstico recomenda a busca de uma única condição que resuma todo o quadro clínico, o paciente idoso é freqüentemente acometido de mais de um agravo, com um conjunto de queixas provenientes de mais de uma doença justificando uma assiduidade maior aos serviços de saúde ${ }^{(12)}$. Contudo, jamais se deve ter um atendimento especializado, fragmentado, que promova o esquartejamento do paciente em múltiplas consultas e pareceres de duvidoso valor.

À Unidade de Atendimento de Enfermagem (UAE), além de suas obrigações rotineiras, poderia ser reservado, experimentalmente, um programa de seguimento de condições consideradas como mais prevalentes e que poderiam ter duas periodicidades de consultas. Por exemplo: uma consulta trimestral na UAM 
e uma consulta mensal de seguimento na UAE. Assim, apenas a título ilustrativo, pacientes hipertensos, obesos, diabéticos, portadores de insuficiência cardíaca, infecção urinária crônica, doença pulmonar obstrutiva crônica, após uma primeira consulta na UAM, teriam um plano de seguimento prioritariamente realizável na UAE. Caso a evolução estivesse de acordo com o plano, a consulta na UAE seria suficiente e só decorrido um certo prazo ou número de consultas, voltaria o paciente à UAM para um novo esquema ou alta.

A Unidade de Atendimento de Psicologia (UAP) caberia tanto a realização de trabalho a nível emocional individual, com entrevistas psicológicas e consultas específicas, bem como a constituição de atividades em grupo, que se valendo de técnicas operativas ou de outra natureza, buscassem maior integração dos idosos e mais eficiente compreensão das angústias, ansiedades e conflitos. Neste particular, poderia ser uma estratégia-tentativa a composição de grupos de família.

Caberia relembrar diretriz do Ministério da Previdência e Assistência Social que reza: "A permanência do idoso na família é fator decisivo para prevenir sua marginalização"(14). Com tal propósito, a UAP, integrada à UAS, poderia esclarecer as situações em que o velho seja encarado como um ônus psicológico ou financeiro, procurando redefinir as questões particulares existentes.

A Unidade de Atendimento de Serviço Social (UAS) realizará basicamente consultas visando ao reconhecimento da situação social de cada paciente, destacando os aspectos vinculados à própria manutenção, moradia e àqueles pertinentes aos direitos e garantias previdenciários, criando e divulgando facilidades para a conquista e o exercício dos mesmos. Poderá ser objetivo adicional a realização também de reuniões diversas e o estudo da viabilidade da execução de trabalhos produtivos, tanto nas habilitações prévias (quando possível), como em aptidões novas: grupos de costura, carpintaria, mecânica, impressão, encadernação etc. ${ }^{(18)}$
REVISTA BRASILEIRA DE EDUCAÇÃO MÉDICA

Um esquema alternativo poderia prever a realização da primeira consulta através da UAS que, brevemente, traçaria um perfil médicosocial do idoso que busca o Ambula-tório, encaminhando-o prioritariamente à própria UAS, à UAP, à UAE ou à UAM.

A relevância que se pretende tenha a UAS advém secundariamente do valor fundamental da questão laboral nos programas destinados aos idosos. A despeito de não termos alcançado dados nacionais, acreditamos que, nesse particular, a experiência nos grandes centros brasileiros: "Há 30 anos... metade dos homens de 65 anos ou mais eram economicamente ativos. Hoje, nessa faixa etária, apenas um homem em cada cinco ou uma mulher entre doze, trabalham"(9)(*).

Se, por um lado, isto poderia traduzir um inegável avanço das políticas previdenciárias, por outro, pode representar um processo compulsório de marginalização e, como conseqüência, o estabelecimento de estigmas e de dependência econômica e psicológica. Talvez, em maior prazo, um dos programas a serem desenvolvidos a nível de pesquisa gerontológica e de atuação transformadora voltar-se-ia para a análise de tais situações, questionando, sob um enfoque multidisciplinar, a necessidade da atividade. Estudos da Organização de Cooperação e Desenvolvimento Econômico (OECD) recomendam que se reintegrem os velhos aos sistemas de produção e consumo, observando que, de fato, persiste uma discriminação social resultante de preconceitos injusticáveis ${ }^{(4)}$.

Mais do que a plena manutenção do idoso na força de trabalho (talvez utópica na atual ordenação das formas de produção) dever-se-ia evitar que a aposentadoria e o descanso ao invés de recompensa

(*) Hoje, os Estados Unidos gastam com o auxílio a seus 20 milhões de velhos e aposentados o equivalente ao nosso Produto Nacional Bruto(19). Ainda assim, os programas são tidos como amplamente deficientes. E mesmo em países como a Inglaterra, onde a assistência social funciona razoavelmente bem, 30 em 100 aposentados necessitam novos empregos para complementação do que recebem do Estado(20). 
por longos anos de trabalho se transforme em duro castigo ${ }^{(19)}$. "Quando um empregado se aposenta, costuma receber elogios do patrão, gracejos invejosos dos colegas, discursos. As vezes, ganha até presentes. Mas tudo isso representa... encostá-lo num canto, como um bagaço, um limão já espremido ou um urso de brinquedo"(19).

\section{Conseqüências-Motivos do Projeto}

I - A primeira grande ambição do sistema sugerido é o de ser essencialmente multidisciplinar, não procurando sobrepor nenhuma atividade (na especificação aqui apresentada, a consulta) sobre as demais. Acreditamos que seja uma técnica ainda inovadora em nosso meio e, principalmente, ajustável a uma situação (a velhice) onde a multidisciplinaridade facilita a compreensão das questões e o atendimento das necessidades

II - Como uma decorrência de todo o projeto, em especial, das atividades UAM-UAE, poderá ser obtida uma sensível redução das taxas de internação e de permanência hospitalares, prevenindo situações obviamente perniciosas, tais como o hospitalismo ou a "solução" asilar. Neste sentido, caberia inclusive a nível de pesquisa o desenvolvimento de metas mais detalhadas que esclarecessem melhor os vícios de um sistema de saúde baseado na hospitalização excessiva e desnecessária; muitas vezes, para um organismo mais debilitado, fatal.

III - Apresente proposta tem em mente que, além dos profissionais efetivos, as diferentes unidades compreendam em seus quadros e pesquisas, estudantes e estagiários; trata-se, também, de preocupação já manifesta pelo Ministério da Previdência e Assistência Social ${ }^{(15)}$.

IV - A experiência ora aqui em elaboração poder-se-á constituir em um importante campo de estudos da Geriatria e Gerontologia, propondo modelos alternativos para o cuidado integral do idoso em nosso meio.

\section{Referências Bibliográficas}

${ }^{1}$ AMANCIO, A. - Os processos biológicos do envelhecimento. Res. méd., 8:6,1979.

2 AMANCIO, A. - As perspectivas da Geriatria. J. Bras. Med., 5:115, 1961.

${ }^{3}$ AMANCIO, A. - O problema social da velhice. In: AMANCIO, A. \& CAVALCANTI, P.C.U. - Clínica Geriátrica. Rio de Janeiro, Atheneu, 1975. p. 5-11.

${ }^{4}$ AMANCIO, A. - Um centro geriátrico. Rev. Méd. Est. Guanab., 36: 325, 1969.

${ }^{5}$ AMANCIO, A. - Relação médico-paciente em Geriatria, In: AMANCIO, A. \& CAVALCANTI, P.C.U. -Clínica Geriátrica . Rio de Janeiro, Atheneu, 1975. p. 13-17.

${ }^{6}$ APOSENTADORIA: o caminho do esquecimento. Jornal do Brasil, 2 set. 1973.

${ }^{7}$ CARNEIRO, A.P. - Atualidade do envelhecimento dos povos. Aula magna pronunciada na abertura dos cursos da UERJ, 1979. (cópia gentilmente cedida pelo autor).

${ }^{8}$ CARVALHO, L. de F. - Padrões mínimos de organização e administração de serviços de atendimento ao idoso. Rev. paul. Hosp., 26:100, 1978.

9 ESPERANÇA de vida: fatos e tendências. Bol. Epidemiol. 5:141,1973.

${ }^{10}$ ESPERANÇA de vida ao nascer. Bol. Epidemiol., $4: 89,1972$.

11 FUNDAÇÃO INSTITUTO BRASILEIRO DE GEOGRAFIA E ESTATÍSTICA - Anuário Estatístico do Brasil (anos diversos).

${ }^{12}$ FURTADO, A.B. - Aspectos da mortalidade na Guanabara, de 1950 a 1973. Rev. Méd. Est. RJ, 42:263,1975.

${ }^{13}$ HOLANDA, T. - Médico diz que velhice deve ser tratada com humanidade. Jornal do Brasil, 8 abr. 1963. 
${ }^{14}$ LAURENTI, R. - Mortalidade infantil e desenvolvimento sócio-econômico: o caso de São Paulo. Rev. Bras. Pesq. Méd. Biol., 11:297, 1978.

${ }^{15}$ OZBEKHAN, H. - Toward a general theory of planning. In: JANTSCH, E. (Ed.) - Perspectives of planning. Paris, O.E.C.D., 1969, p. 84.

${ }^{16}$ SAUVY, A. - La fin des riches. Paris, Calman Levy, 1975.

${ }^{17}$ SILVA, L.G. do N. e; VELLOSO, L.A.P. \& CANDAU, M. de C. - Política social para o idoso: diretrizes básicas. Rev. Paul. Hosp., 26:229, 1978.
REVISTA BRASILEIRA DE EDUCAÇÃO MÉDICA

${ }^{18}$ SINDICATO DOS MÉDICOS DO RIO DE JANEIRO - Alguns aspectos sobre as condições de saúde no município do Rio de Janeiro. Rio de Janeiro, 1979. 46f. (mimeo.).

${ }^{19}$ SOMMERS, A.R. - Violence, television and the health of american youth. New Engl. J. Med., 294:811, 1976.

${ }^{20}$ VELHOS: o novo desafio. Realidade: 21, mar. 1969. 